\title{
Local deformation method for measuring element tension in space deployable structures
}

\author{
Sergey Belov ${ }^{1, *}$, Mikhail Pavlov ${ }^{1}$, Viktor Ponomarev ${ }^{1}$, and Sergey Ponomarev ${ }^{1}$ \\ ${ }^{1}$ National Research Tomsk State University, 634050 Tomsk, Russia
}

\begin{abstract}
The article describes the local deformation method to determine the tension of cord and thin membrane elements in space deployable structure as antenna reflector. Possible measuring instrument model, analytical and numerical solutions and experimental results are presented. The boundary effects on measurement results of metallic mesh reflector surface tension are estimated. The study case depicting non-uniform reflector surface tension is considered.
\end{abstract}

\section{Introduction}

As mentioned in [1] deployable space structures as antenna reflector are widely used because of their effective deployment within significant coverage and relatively small mass. Nowadays, research work concerning deployable antenna reflector are very actual because of growing communication, monitoring and observation of Earth systems. Some of them could be found in [2-5].

In antenna designing it is crucial not only to control cord element tension, being loadbearing elements, but also reflector metal mesh surface tension. Dynamic characteristics (such as natural frequencies) depend on cord element tension, while reflector surface tension significantly influences its radio - reflective properties. Measuring both cord and reflector surface tension is based on the local deformation method (LDM). This is a quasistatic method for material testing via mechanical enforcement on a solid body surface. In the present work LDM involves the following: tested element (cord or metallic mesh) exposed to given strain. In this case the deformation resistance force is measured, defining the initial tension.

\section{Analytical expressions to determine initial cord and membrane tension}

Obtained initial cord tension expression to given depth indention and force is applied in the following problem. Cord with cross-section $S$, initial length $L$ and modulus of elasticity $E$ has initial tension $T_{0}^{c}$ and is fixed at the ends. Centrally, load $P$ acts on the cord, bending the cord to corresponding value $H$. It is necessary to determine the initial tension value in terms of $P$ and $H$ values. Cord elongation could be as following:

\footnotetext{
*Corresponding author: belovsv@niipmm.tsu.ru
} 


$$
\Delta=\frac{\left(T-T_{0}^{c}\right) L}{E S}-\frac{D}{2 T^{2}}
$$

where, $T$ - cord tension under load, $D=\int_{0}^{L} Q^{2} d x, Q-$ transverse force in the cord. If in (1) $Q$ is the concentrated load centrally applied, then the expression for cord initial tension is the following:

$$
T_{0}^{c}=\frac{L P}{4 H}-\frac{2 H^{2} E S}{L^{2}}
$$

If (2) is divided by $S$, then cord initial stress is the following: $\sigma_{0}^{c}=\frac{L P}{4 H S}-\frac{2 H^{2} E}{L^{2}}$.

Analytical expression (3) for circular membrane initial tension is defined by the virtual work principle [6]:

$$
\sigma_{m}^{0}=\frac{P_{m}}{2 I H_{m} \pi}
$$

where, $I=\int_{d}^{b}\left[B^{2}\left[1-\frac{1}{\sqrt{1-H^{2} B^{2}}}\right]-\frac{1}{r} \int_{b}^{r} \frac{B^{2}}{\sqrt{1+H^{2} B^{2}}} d r\right] r d r, B=\frac{r\left(B_{1}-2 r^{2}\left(b^{2}+d^{2}\right)\right)}{b^{4}-d^{4}+4 b^{2} d^{2} \ln \frac{d}{b}}$, $B_{1}=4 b^{2} r^{2} \ln \frac{r}{b}+2 b^{2}\left(d^{2}+r^{2}\right), \quad b-$ circular membrane radius, $P_{m}-$ centrally uniform membrane lateral load applied on the circle radius $d, H_{m}$ - maximum membrane depth of indention in the circle of radius $d$.

\section{Experimental results in measuring initial cord and membrane tension}

Figures $1 \mathrm{a}$ ), b) show experimental units to measure initial cord and membrane tension, respectively, as well as to justify expression (2) - (3).

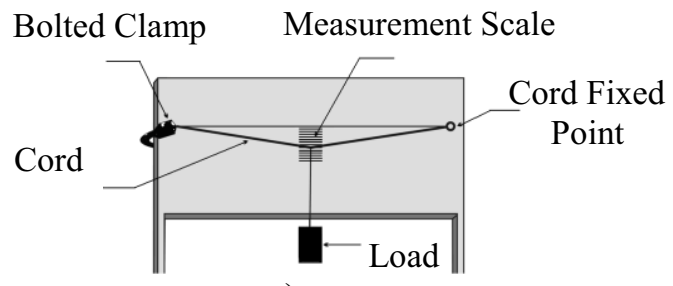

a)

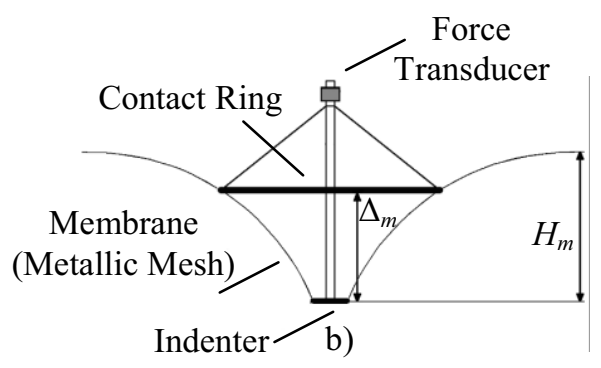

Indenter b)

Fig. 1. Diagram of experimental units: a) for cord element b) for membrane element. 


\subsection{Cord initial tension measurement}

Aramide - wired cord with glass core of $0.8 \mathrm{~mm}$ in diameter and circular cross-section was used in the experiment. If the cord strain is less than $0.3 \%$, then the linear stress-strain dependency exists. In case of $90^{\circ}$ rotation relative to illustrated position Figure 1a) cord is vertical, while its fixed point is at the top. Load at unfixed end provides cord initial tension $T_{0}^{c}$. After, this end is fixed by bolted clamp and the cord is reversed to initial position with centrally concentrated load $P$. The corresponding cord bending $H$ at this load is measured according to the scale which is positioned to the initial cord position without a load. Then, $H$ and $P$ values are put in (2) which expresses experimental initial cord tension values. These values are compared with respective $T_{0}^{c}$. In the experiment, $T_{0}^{c}=1,2,3 \mathrm{kgf}$ values were considered. It was shown that the differences between $T_{0}^{c}$ and values obtained by (2) are not more than $10 \%$. Thus, the expression (2) is justified.

\subsection{Membrane initial tension measurement}

To measure the membrane (metallic mesh) initial tension, the strain is set to its normal. On the experimental unit (Figure 1b) the bending depth is controlled by the contact ring. In the experiment the contact ring plane is parallel to the membrane tangent plane. Indenter presses into the membrane until the contact ring touches the membrane surface. At this moment the membrane resistance force is measured by the force transducer. Depth of indention $H_{m}$ is determined as the $\Delta_{m}$ distance between contact ring plane and indenter edge.

In the experiment the square metallic mesh membrane of $25 \times 25 \mathrm{~cm}$ was used. Each side was subjected to the distributed load. The side total loads were $0.1 ; 0.2 ; 0.3 \mathrm{kgf}$ for each experiment, respectively. The inital membrane uniform tensions were $4 \cdot 10^{-3} ; 8 \cdot 10^{-3} ; 12 \cdot 10^{-3}$ $\mathrm{kgf} / \mathrm{cm}$. Cardboard contact ring and indenter of $2.5 \cdot 10^{-3} \mathrm{~kg}$ were positioned in the membrane center. Indenter contact surface is a circle with diameter of $3 \mathrm{~cm}$. Loads $P_{m}=3 \cdot 10^{-3} ; 4 \cdot 10^{-3}$; $5 \cdot 10^{-3} \mathrm{kgf}$ were imposed on indenter. Thus, the total loads (taking into account mass of indenter) on membrane were $5.5 \cdot 10^{-3} ; 6.5 \cdot 10^{-3} ; 7.5 \cdot 10^{-3} \mathrm{kgf} . \Delta_{m}$ distance was measured by cathetometer with accuracy of $0.1 \mathrm{~mm}$. $H_{m}$ value was calculated by analytical formula for relevant problems of [7]. Additionally, the same experiments were done for a membrane of $22 \times 22 \mathrm{~cm}$ with indenter diameter of $1.5 \mathrm{~cm}$. In this case, the membrane tesion was varied from $3.8 \cdot 10^{-3}$ to $15 \cdot 10^{-3} \mathrm{kgf}$.

To calculate initial membrane tension, the finite element method (FEM) was used [7-9]. Square membrane (with fixed edges) of $25 \times 25 \mathrm{~cm}$ was modeled by shell elements of first order with initial tension option. Its modulus of elasticity is $E_{m}=2 \cdot 10^{2} \mathrm{kgf} / \mathrm{cm}^{2}$, Poisson ratio is $v=0.29$, material properties are isotropic.

Indenter action was modeled by the forces applied to the nodes in the indenter and membrane contact region of $0.75 \mathrm{~cm}$ radius .

Based on analytical expression (3), experiments measurement and FEM solutions, depth of indention $H_{m}$ dependency on $\sigma_{m}^{0}$ for different load values $P_{m}=5.5 \cdot 10^{-3} ; 6.5 \cdot 10^{-3} ; 7.5 \cdot 10^{-}$ 3 kgf were calculated. It was shown that the differences between $H_{m}$ obtained experimentally are no more than $15 \%$ comparable to ones obtained by (3) and FEM solutions. Thus, expression (3) could be justified for membrane initial tension calculation.

In the estimation of boundary membrane closeness effects to the points of measurment, it was shown that if membrane measuring regions are twice more than the contact ring diameter, then membrane boundary effects are insignificant. If these regions are less than 
the contact ring diameter, the membrane boundary effects are significant (i.e. membrane force resistance increases to indenter load).

It is important to consider the case of membrane biaxial tension with different components of principal stresses $\sigma_{x m}^{0}, \sigma_{y m}^{0}$. For this purpose, indenter with elongated shape was used (Figure 2).

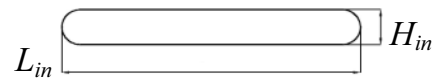

Fig. 2. Indenter with elongated shape.

In this case, resistance force depends on depth indention, membrane tension and indenter orientation in the $(x, y)$ - plane. Indention was modeled by FEM where contact membrane shell elements with non-uniform tension were used. For above described indenter of length $L_{i n}$, the rounded radius is the half of its width $\rho=H_{\text {in }} / 2$. Tension along axis $x$ is constant, i.e. $\sigma_{x m}^{0}=5 \cdot 10^{-3} \mathrm{kgf} / \mathrm{cm}$. Tension along axis $y$ is varible witin $\sigma_{x m}^{0}=2 \cdot 10^{-3}-12 \cdot 10^{-3}$ $\mathrm{kgf} / \mathrm{cm}$. Indenter effect was modeled on the basis of given node displacements. It was proved that indenter orientation effect on indention resistance force is more if the indenter is more elongated and bending depth is also more.

\section{Conclusions}

Obtained results proved the following: a) LDM could be effectively applied to determine initial tension in cord and membrane elements of space deployable structures as antenna reflector; b) analytical expressions (2)-(3) for cord and membrane initial tensions are in a full agreement with experiment and numerical results; c) membrane boundary effects should be considered in the regions where it is less than the contact ring diameter; $d$ ) in case of non-uniform membrane tension, elongated indenter could be applied.

This work has been financially supported by Ministry of Education and Science of Russian Federation. Unique identifier RFMEFI57814X0073.

\section{References}

1. A. Belkov, S. Belov, M. Pavlov, V. Ponomarev, S. Ponomarev and A. Zhukov, Matec Web of Conf. 48, 02001 (2016)

2. V.N. Zimin, I.M. Koloskov, V.E. Meshkovsky, V.I. Usyukin J. Trans. Mod. and Sim. 30, 497 (2001), https://www.witpress.com/Secure/elibrary/papers/CMEM01/CMEM01049FU.pdf

3. S. Morterolle, B. Maurin, J-F.Dube, J. Averseng, J. Quirant, J. Aerosp. Sci. and Tech. 42, 74 (2015)

4. K. Tanizawa, K. Yamamoto, J. Theor. and Appl. Mech. Jap. 53, 75 (2004)

5. J. Santiago - Prowald, H. Baier, J. CEAS Space, 5, 89, doi: 10.1007/s12567-013-00483 (2013)

6. K. Washizu, Variational methods in elasticity and plasticity (Pergamon Press Ltd., Oxford, 1975)

7. B.L. Abramian et al., Prochnost', ustojchivost', kolebanija. Spravochnik v treh tomah. T.1. (M: Mashinostroenie, 1968) (in Russian)

8. P. Wriggers, Nonlinear Finite Element Method (Springer, Berlin, Heidelberg, 2008) 